\title{
Epidermoid cyst of the pineal region
}

\author{
M. SAMBASIVAN AND AMMU NAYAR \\ From the Department of Neurosurgery, Medical College, Trivandrum, India
}

SYNOPSIS An epidermoid cyst in the pineal region is reported to underscore the feasibility of successful surgical excision of such lesions and the need to review the management of posterior third ventricular lesions. An interesting, but unexplained, feature in this patient was renal glycosuria which cleared after excision of the tumour.

Epidermoid cysts constitute $0 \cdot 2-1 \%$ of intracranial tumours (Russell and Rubinstein, 1963) and are generally found at the base of the brain. They rarely occur in the pineal region and a search through the literature yields only nine reported cases (Kirsch and Stears, 1970; Stein et al., 1972).

\section{CASE REPORT}

A 51 year old man was admitted to the general medicine unit for severe headache and occasional vomiting of 15 days' duration. The headache was worse on assuming the erect posture and was associated with fainting attacks and generalized convulsions. He also complained of blurred vision. Two months before admission he had noticed polyuria and polydipsia, for which he had a medical consultation. He was found to be diabetic and insulin was prescribed. He had been married for 22 years, had six children, and led a normal marital life.

On examination, the pulse rate was 60 per minute and he had a labile blood pressure, systolic pressure ranged from 100 to $170 \mathrm{mmHg}$ and diastolic pressure 70 to $100 \mathrm{mmHg}$. There was no neurological deficit.

Routine haematological and serological investigations, plain radiograph of the skull, and electro-

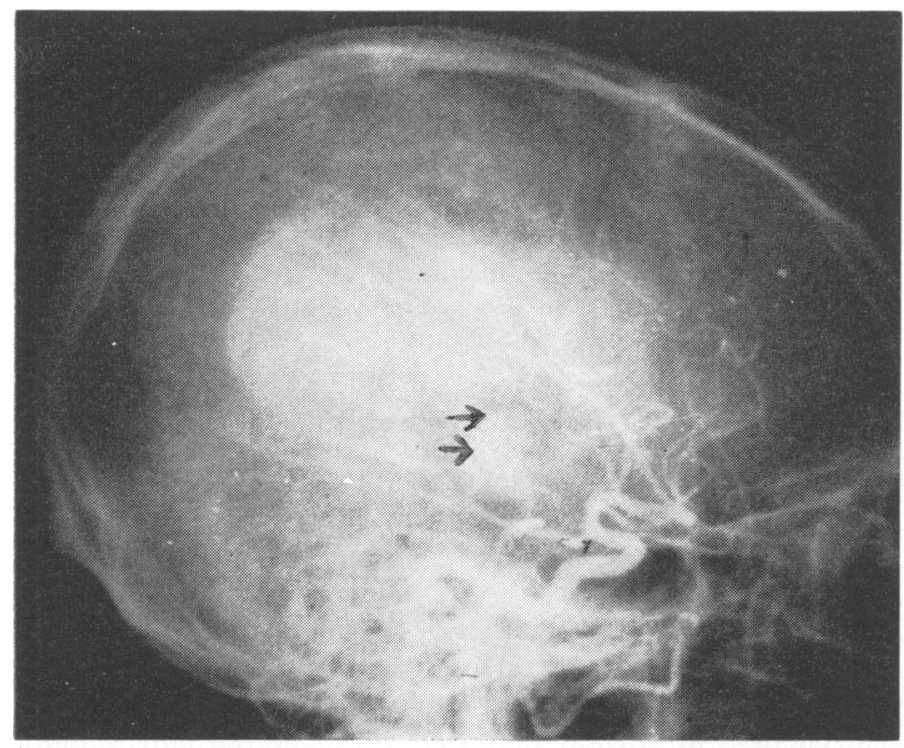

FIG. 1. Meglumine iothalamate ventriculogram with the carotid angiogram shows a filling defect in the posterior third ventricle. 
encephalogram were normal. He felt better on symptomatic treatment with intravenous mannitol and oral glycerine, and was discharged from hospital. He returned after 23 days with recurrence and aggravation of symptoms. He was now referred to the neurosurgery department. On examination, his general condition was poor. He appeared dehydrated and drowsy. He had bilateral partial ptosis with loss of upward gaze. There were pyramidal tract signs bilaterally. Evaluation of the sensory system was not possible. The only abnormal finding on laboratory investigation was $0.5 \%$ sugar in the urine and a trace of ketone bodies. The latter disappeared after parenteral fluid therapy but a trace of sugar remained. The fasting blood sugar was $110 \mathrm{mg} / \mathrm{dl}$ and one hour after food $140 \mathrm{mg} / \mathrm{dl}$.

There was bilateral slowing in the electroencephalogram. The echoencephalogram showed widening of the midline echo indicating probable dilatation of the 3rd ventricle. A plain radiograph of the skull was non-contributory. In a ventriculogram with meglumine iothalamate (Fig. 1) there was a filling defect in the posterior third ventricle, with extension to the right causing a filling defect in the right lateral ventricle. A right carotid angiogram showed elevation of the branches of the middle cerebral artery, in the posterior part, with a fetal type of posterior communicating artery going on to the posterior cerebral artery, which appeared to be stretched. The posterior choroidal artery appeared distorted and pushed forwards.

The clinical localization being confirmed, the possibility of a third ventricular tumour of the nature of a pinealoma, glioma, or ependymoma was considered. Prompted by past experience of a direct approach to these lesions (Sambasivan, 1972), it was decided to explore the pineal region through a right parieto-occipital approach.

OPERATION A parieto-occipital bone flap was turned. The dura mater was under severe tension and relaxation of the brain was obtained by ventricular drainage. The dura mater was opened and the dural flap was turned down, hinged on the transverse sinus. The posterior parietal gyri were absolutely flattened and, on probing, a tumour was felt at a depth of $1 \mathrm{~cm}$. On retracting the parieto-occipital region a pearly tumour was encountered which protruded into the right lateral ventricle. Meanwhile, the right lateral ventricle was opened. The tumour was removed piecemeal. The capsule of the tumour was dissected off easily from the falx and tentorium. It was adherent to the great vein of Galen and straight sinus and was peeled off with difficulty. The tumour extending into the posterior 3rd ventricle was removed in toto, with the capsule. There was a blood loss of about $200 \mathrm{ml}$.
The dural flap was replaced and sutured. The bone flap was also replaced and the scalp wound closed in layers.

The patient had a smooth postoperative period. On the second postoperative day he was fully alert, answering questions, and taking feeds orally. The Parinaud's phenomenon had disappeared. By the fifth postoperative day the pyramidal tract signs had reversed. There was no glycosuria and the fasting blood sugar was $105 \mathrm{mg} / \mathrm{dl}$. One month later the patient was able to look after himself with no deficit. His glycosuria had disappeared.

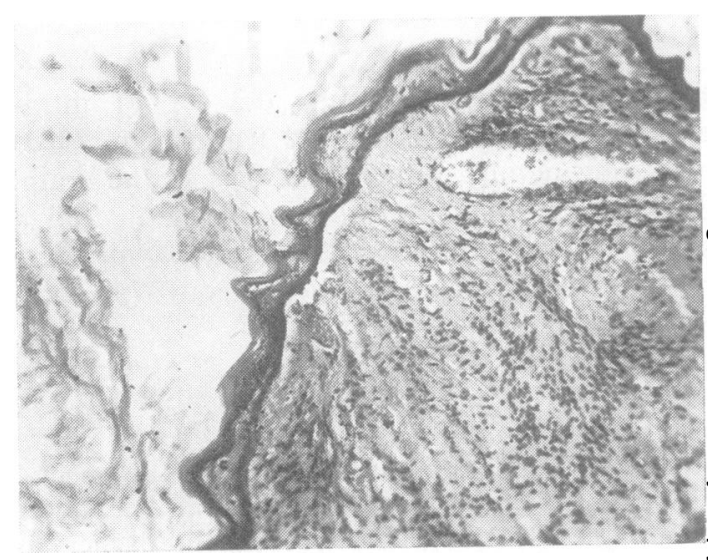

FIG. 2. Wall of cyst lined by squamous epithelium Laminated keratin overlies it, $\times 210$.

HISTOPATHOLOGY Sections from the cyst wall showed laminated keratin overlying stratified squamous epithelium which formed the lining of the cyst. Keratohyaline granules were present in the superficial epithelium. Glial tissue lay beneath the epithelium. Skin adnexal structures were not present (Fig. 2). Histology confirmed the operative findings of an epidermoid cyst.

\section{DISCUSSION}

Cranial epidermoid and dermoid cysts arise from tissue sequestrated during closure of the neural tube. The epithelial remnants persist and grow into these cystic lesions. Since these tumours occur along lines of fusion, they could theoretically be found anywhere within or outside the skull. However, in practice, epidermoids occur at certain favoured sites-in the subarachnoid 
space at the base of the brain, the diploe of the skull, and within the brain substance (Tytus and Pennybacker, 1956). They are uncommon over the vertex of the brain. The pineal gland, which is well known as the site of a teratoma, is rarely the seat of an epidermoid cyst.

The management of tumours of the posterior third ventricular region has been the subject of much controversy. Neurosurgeons from the days of Cushing have regarded radical surgery in the pineal region as a hazardous procedure. This has led to the conservative approach of radiation and a shunt (Cummins et al., 1960; Cole, 1971). More recently, however, there are reports of single and series of cases where direct surgical exploration was successfully attempted (Kunicki, 1960; Suzuki and Iwabuchi, 1965; Kirsch and Stears, 1970; Sambasivan, 1972). The case reported here emphasizes the need to explore the pineal region surgically. Radiological procedures do not always provide an accurate answer to problems in the pineal area, so that the advantages of a direct surgical attacknamely, histological determination and total extirpation of a benign lesion-cannot be ignored. While it is realized that benign lesions in this area are rare, it is also true that this region has been poorly explored and therefore the actual incidence of tumour types is not known.

An unexplained feature in this patient is renal glycosuria which disappeared after excision of the tumour. The pineal gland once considered a vestigial organ, is now known to exert a control on endocrine function. This case suggests a link between the pineal and renal tubular function and this aspect needs further investigation.

Our thanks are due to Mr. G. Madhaven Nair for preparing the histological sections.

\section{REFERENCES}

Cole, H. (1971). Tumours in the region of the pineal. Clinical Radiology, 22, 110-117.

Cummins, F. M., Taveras, J. M., and Schlesinger, E. B. (1960). Treatment of gliomas of the third ventricle and pinealomas; with special reference to the value of radiotherapy. Neurology (Minneap.), 10, 1031-1036.

Kirsch, W. M., and Stears, J. C. (1970). Radiographic identification and surgical excision of an epidermoid tumor of the pineal gland. Case report. Journal of Neurosurgery, 33, 708-713.

Kunicki, A. (1960). Operative experiences of eight cases of pineal tumor. Journal of Neurosurgery, 17, 815-823.

Russell, D. S., and Rubinstein, L. J. (1963). Pathology of Tumours of the Nervous System. Arnold: London.

Sambasivan, M. (1972). Posterior third ventricular tumors. In Present Limits of Neurosurgery, pp. 165-168. Edited by I. Fusek and Z. Kunc. International Congress Series No. 272. Excerpta Medica: Amsterdam.

Stein, B. M., Fraser, R. A. R., and Tenner, M. S. (1972). Tumours of the third ventricle in children. Journal of Neurology, Neurosurgery, and Psychiatry, 35, 776-788.

Suzuki, J., and Iwabuchi, T. (1965). Surgical removal of pineal tumors (pinealomas and teratomas). Experience in a series of 19 cases. Journal of Neurosurgery, 23, 565-571.

Tytus, J. S., and Pennybacker, J. (1956). Pearly tumours in relation to the central nervous system. Journal of Neurology, Neurosurgery, and Psychiatry, 19, 241-259. 